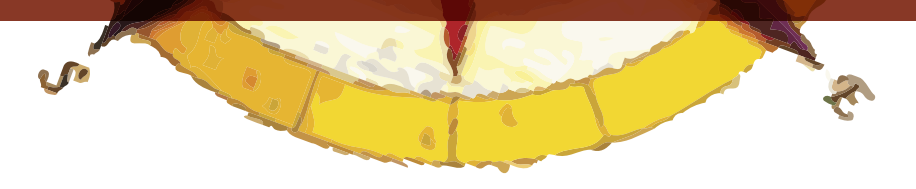

\title{
AS DIMENSÕES ESCALARES E A ABORDAGEM DE CONTEÚDOS GEOGRÁFICOS
}

\author{
Valéria de Oliveira Roque Ascenção ${ }^{53}$ \\ Roberto Célio Valadãos4
}

\section{RESUMEN}

En este artículo se tratará de presentar algunas consideraciones metodológicas sobre los posibles caminos en la enseñanza de la geografía. Para ello, se centrará en el enfoque de la ampliación de un fenómeno. El debate se centrará en las posibilidades que plantea la escala de experiencia en la enseñanza de la geografía y de cerca, pero, en la distribución espacial de los fenómenos relacionados con los contenidos adecuados. Se entiende la escala es una referencia esencial para la interpretación de la dispersión espacial de un fenómeno.

Palabras clave: Escuela de Geografía de la metodología de la enseñanza; Escala de tamaño, espacialidad.

\section{RESUMO}

Este artigo buscará apresentar algumas ponderações referentes aos caminhos metodológicos possíveis no ensino de Geografia. Para tanto, ele se centrará na abordagem escalar de um fenômeno. As reflexões terão como foco possibilidades postas pela escala do vivido no ensino de Geografia e, mais detidamente, na espacialização de fenômenos que envolvam o conteúdo relevo. Compreende-se a escala como um referencial imprescindível à interpretação da dispersão/abrangência espacial de um fenômeno.

Palavras-chave: Geografia Escolar, Metodologia de ensino, Dimensão escalar, Espacialidade.

\begin{abstract}
This article will try to present some methodological considerations concerning the possible paths in the teaching of geography. To do so, will focus on scaling approach of a phenomenon. The reflections will focus on possibilities posed by the scale experienced in teaching geography and more closely, the spatial distribution of phenomena involving relevant content. It is

53 Professora-adjunta do Departamento de Geografia da Universidade Federal de Minas Gerais.

54 Professor associado do Departamento de Geografa da Universidade Federal de Minas Gerais.
\end{abstract}


understood the scale as an essential reference to the interpretation of the dispersion /spatial extent of a phenomenon.

Keywords: Geography School, teaching methodology, size scaling, Spatiality.

\section{INTRODUÇÃO}

Considera-se pertinente afirmar que os últimos quinze anos têm sido profícuos quanto a proposições e à realização de reflexões sobre o ensino de Geografia, sobretudo, em sua versão na escola básica. Tal movimento agregou debates, pesquisas e propostas referentes a ações internas nas salas de aula dessa disciplina, como também à formação de seus docentes e à elaboração de orientações curriculares. Não se intenciona apresentar um arrazoado do que foi produzido até o momento; tarefa esta que exigiria tempo e espaço maior do que um artigo. Faz-se aqui somente uma breve demarcação de um movimento que ganha força no seio do qual se instala este trabalho.

Muitas temáticas sobre o ensino de Geografia foram e são abordadas nas inúmeras linhas de pesquisas espalhadas pelo Brasil, deixando à vista as marcas das divergências e convergências, necessárias à Ciência e às renovações. Contudo, mesmo correndo os riscos inerentes à generalização, considera-se possível hoje, para o ensino de Geografia, um relativo consenso quanto à sua finalidade: favorecer ao educando a construção de raciocínios com base na inteiração dos componentes espaciais (relevo, sujeitos sociais, aparelhos urbanos e rurais, hidrografia, clima).

Talvez, tentativas em se identificar caminhos possíveis para a construção desse raciocínio espacial justifiquem o volume de trabalhos dedicados à metodologia de ensino em Geografia. Um breve exame nos Anais do Encontro Nacional de Práticas de Ensino de Geografia (ENPEG, 2011) e do Encontro Nacional da Associação Nacional de Pós-Graduação e Pesquisa em Geografia (ENANGEO, 2011) pode confirmar a afirmativa anterior. Tal constatação é motivo de satisfação, pois sugere o desejo no aprofundamento do olhar sobre a Geografia Escolar, dando destaque aos sujeitos que a protagonizam, aos conhecimentos que a constituem e as ações efetivas com esse conteúdo nas salas de aula da educação básica brasileira.

Entretanto, esse quadro aparentemente auspicioso não faz impertinente perguntar: Afinal, em que efetivamente mudou as metodologias de ensino, nas práticas pedagógicas brasileiras, referentes aos conhecimentos geográficos? Respostas extremadas, tais como, tudo ou nada, não acrescentam ou favorecem a continuidade dos debates. Talvez, sejam incipientes as tentativas de renovação das práticas, mas infere-se que elas existam. Sugere-se mesmo que parte dos trabalhos de caráter metodológico divulgados nos eventos inspira docentes "entusiasmados" a investirem em suas aulas. Ainda assim, se apontam limites tanto no acesso dos professores ao que se discute como àquilo que se discute.

Avalia-se que, as dimensões metodológicas, sejam pedaços dos "azulejos" que formam o intrincado mosaico da Geografia Escolar. Contudo, arrisca-se a afirmar que a metodologia de ensino seja talvez o "azulejo" que harmoniza conhecimento e ensino. Nesse sentido, reflexões que a considerem exigem estofo teórico, o que, diz-se modestamente, se percebe escasso em muitos dos trabalhos que se ousam a debater metodologicamente o ensino de Geografia. Arvora-se, mesmo sabendo do perigo que se corre, afirmar que inúmeros artigos se restringem a relatar experiências, interessantes, importantes em sua realização, mas carentes em profundidade teórica. 
Este artigo traz a marca da pretensão, pois buscará infiltrar-se na delicada discussão metodológica, inevitável, acredita-se, para todos que pretendem transformações na versão escolar de uma disciplina, neste caso, a Geografia. Com esse objetivo se buscará apresentar aqui algumas ponderações referentes aos caminhos metodológicos possíveis no ensino de Geografia. Para tanto, se centrará na abordagem escalar de um fenômeno, exemplificada por meio do trabalho com o conteúdo relevo. A pretensão fica a cargo da crença de que aqui se avançará, ainda que discretamente, em um diálogo com a teoria, indo para além da pura experiência.

Se a função primordial da Geografia Escolar na atualidade brasileira é munir os sujeitos com referenciais que os favoreça refletir sua cotidianidade (imediata ou não), a escala, dimensão indelével da ciência geográfica, ganha destaque. Antecipam-se argumentos vindouros afirmando que as bases escalares que sustentam práticas em Geografia alicerçam as leituras de mundo, permitindo que próximo e distante sejam tomados somente como ordem de grandeza.

Aproximar do cotidiano significa restringir-se ao visível? O vivido encerra-se em si mesmo ou é uma porta aberta ao trânsito entre vividos outros? Em qual medida o visível deixa entrever o "invisível"? Mais do que responder aos questionamentos anteriores, este artigo possivelmente gerará argumentos que somem polêmicas a essas perguntas.

Tentando aclarar a discussão, se iniciará com uma concisa abordagem acerca do fazer geográfico, identificando pontos de distanciamento e aproximação entre o fazer do bacharel e o fazer do licenciado. Pretende-se defender que, ao longo do pensamento geográfico, certamente com algumas variações, certas inteirações e categorias espaciais mantiveram-se na base das interpretações geográficas. Assim consideradas, como base das análises geográficas, tais interações e categorias compõem tanto a Geografia Acadêmica como a Geografia Escolar; tanto o trabalho técnico do bacharel como o exercício da docência na educação básica. Afirma-se a escala como um desses elementos comuns e que permaneceram no fazer geográfico.

Posteriormente, se trará ao texto posições de outros autores que tomam a escala como umas das fundações que sustentam as análises geográficas; que como indicadora da abrangência de um fenômeno, infere-se, talvez seja central às decisões metodológicas.

Por fim, se discutirá as possibilidades postas pelo vivido, cotidiano imediato, no ensino de Geografia e, mais detidamente, na espacialização de fenômenos. Nesse momento, de modo a ilustrar o debate, posicionamentos frente ao tratamento escolar de um elemento espacial, se apresentará uma perspectiva para a espacialização de um fenômeno junto aos alunos da educação básica, com base em um conteúdo escolar $\square$ o relevo. Tal proposta sugere uma forma de relevo - a vertente - para o desenvolvimento do conhecimento dessa matéria. Forma esta que, avalia-se, ao mesmo tempo ressalta o valor do local para as aprendizagens geográficas, sem inibir o trânsito escalar, fundamental para a complexidade espacial contemporânea.

\section{O FAZER GEOGRÁFICO}

Nos últimos anos, inúmeros trabalhos na área do ensino de Geografia reforçaram a ideia da alteridade entre a Geografia Escolar e a Geografia Acadêmica (Chervel, 1991). Tal exercício, ainda hoje, é importantíssimo quando se pensa que afirmar a distinção revela as especificidades de cada uma e o imperativo de reflexões específicas, pautadas nessas distinções. 
As disciplinas escolares constituem-se com base em uma série de interações, entre as quais aquelas que envolvem os conhecimentos de um campo disciplinar específico e os conhecimentos que constituem o campo da educação; estão comprometidas com um dado campo do conhecimento, contudo, têm uma finalidade social mais imediata do que uma disciplina acadêmica. Sua finalidade social é outro elemento que a constitui e faz produzir alterações em seus rumos, acrescentando ou retirando conteúdos, estimulando mudanças na metodologia de trabalho pedagógico. A função social de uma disciplina escolar é mutável, flexível e vincula-se diretamente às condições histórico-sociais nas quais ocorrem os processos de ensino e de aprendizagem, ganhando, nesses quesitos, quando comparada à versão acadêmica, agilidade em sua composição.

As disciplinas acadêmicas estão mais diretamente comprometidas com o campo do conhecimento no qual se inserem e, sem que isso configure valor, vinculam-se menos às demandas sociais e mais às necessidades de desenvolvimento de dada ciência. Os currículos formativos da graduação estruturam-se com base na versão acadêmica de campo do conhecimento.

O professor é formado por disciplinas acadêmicas, mas em sua prática pedagógica lida com a versão escolar de uma dada disciplina. Encerram-se aqui inúmeras implicações postas às práticas docentes, entre as quais se destaca a dificuldade ou o despreparo dos professores frente ao necessário reconhecimento de que, nas salas da educação básica brasileira, o conhecimento a ser trabalhado deve, inevitavelmente, ser recontextualizado (Bernstein, 2003) e não reproduzido ou meramente transposto com propõe Chevallard (1991). Nas salas do nível básico de ensino o professor deverá articular os conhecimentos específicos da Geografia aos conhecimentos do campo educacional e simultaneamente às demandas sociais que orientam/orientarão a abordagem de um conteúdo escolar, a fim de favorecer aos alunos leituras sobre o real. Ou seja, é na sala de aula que se produz a Geografia Escolar, daí o imperativo de se formar professores cônscios de tal responsabilidade e portadores de conhecimentos que os permitam assim agirem.

Entretanto, para além das distinções entre os formatos acadêmico e escolar, brevemente apresentadas neste texto, considera-se relevante debruçar-se sobre os pontos de contato, até mesmo, de similaridade entre ambas. A Geografia Acadêmica, da mesma forma que a Geografia Escolar, é uma "derivação" da ciência geográfica. Ambas têm como objeto comum investigar a distribuição espacial dos fenômenos (Gomes, 2009). Portanto, admite-se que a elas sejam comuns temáticas e ações metodológicas. Nesse sentido, tanto os bacharéis como os licenciados precisam realizar raciocínios comuns, assentados sobre as mesmas bases geográficas. Certamente tal afirmativa resguarda as especificidades, distinções e relevância do trabalho desempenhado por cada um deles.

Não se pretende apresentar todas as possíveis aproximações entre a versão escolar e a acadêmica da Geografia, mas, sim, destacar alguns constituintes que permaneceram ao longo da história da ciência geográfica. Tal permanência não deve ser tomada como imutabilidade, pois, como ocorre em toda ciência, a Geografia vem assistindo a redefinições e ressignificações de termos e conceitos, e da convivência com diferentes concepções acerca de seu objeto. Ousa-se apontar traços que, mesmo suscetíveis às alterações destacadas, mantiveram-se constantes na e para a interpretação geográfica.

Inicialmente delimita-se a existência do que aqui se denominou tripé metodológico da Geografia: localizar, descrever e analisar. Coadunando com Cavalcanti (2002), essas ações são orientadas pelas indagações: onde? (localizar); como? (descrever); por quê? (analisar). Mas, coerente com os movimentos das ciências em geral e da ciência geográfica, especificamente, essas noções sofreram 
ressignificações ao longo do tempo e, ainda hoje, podem variar segundo a tendência filosófica que orienta a interpretação geográfica.

Para efeitos deste artigo, a noção de localização transcende variáveis numéricas. Ao procurar responder "onde?" se pretende reunir informações que caracterizem as áreas de ocorrência de um dado fenômeno. Afinal, se se considerar a espacialidade como o efeito de um fenômeno em uma área e, ao mesmo tempo, o efeito de uma área sobre a manifestação de um fenômeno, a localização é um dado altamente relevante. A ação sistematizadora dos dados localizacionais (descrição) exige um intricado exercício associativo com os constituintes (população, economia, indicadores sociais, relevo, vegetação) da(s) área(s) em estudo. Não é, e não pode ser uma ação linear, pois fosse desse modo, se perderia o dinamismo crucial à interpretação espacial. A análise, ou interpretação geográfica, faz interagir os movimentos anteriores (localizar, descrever e interpretar) considerando o referencial teórico que alimenta a investigação; demarcando ou identificando categorias geográficas (a exemplo: lugar, território, região, paisagem); lançando mão de categorias de análise espacial estrutura, processo, função e forma (Santos, 1988); seletividade espacial, marginalização espacial, reprodução da região produtora; antecipação espacial (Corrêa, 1995). Tudo isso arregimentado com o fim de deixar expressar a espacialidade do(s) fenômeno(s) em foco.

O tripé metodológico, os referenciais teóricos, as categorias geográficas e as de análise espacial, aqui assumidos como base para interpretação da espacialidade - distribuição - espacial de um dado fenômeno (Gomes, 2009), em inteiração às categorias Espaço, Escala e Tempo operam para a constituição de uma base soberana, a ciência Geografia.

Com maior ou menor ênfase a depender da fase histórica ou da tendência teórica que orientam os estudos geográficos, afirmam-se, neste trabalho, os aspectos anteriormente destacados como constituintes da interpretação geográfica ou da interpretação da espacialidade do fenômeno ao longo da história dessa ciência, independente da finalidade dessa interpretação. Entende-se que o estudo da espacialidade se dê a partir da confluência dos elementos e movimentos presentes na Figura 1 e que a ausência de qualquer um deles pode favorecer a construção de análise que se afirmam geográfica, mas que de fato não o é, pois deixa ausente a dimensão espacial dos fenômenos (Gomes, 2009).

É provável que afirmar a existência de pontos comuns seja, atualmente, mais polêmico do que alegar a alteridade entre Geografia Escolar e Geografia Acadêmica. Contudo, a identificação de pontos comuns não é menor, sobretudo para a Geografia Escolar, em que os docentes, não raramente, afirmam que determinados raciocínios restringem-se à função dos bacharéis (Roque Ascenção, 2009). Infere-se que, ao pensarem desse modo, os professores de Geografia podem distanciar-se de práticas que contemplem a espacialização dos fenômenos, restringindo-se ao ensino estanque dos diversos componentes espaciais (urbanização, vegetação, relevo, população, industrialização, entre outros). Destaca-se ainda que a atribuição de determinados raciocínios aos bacharéis estende-se ao componente escala, na maioria dos casos, identificado à sua perspectiva cartográfica - dimensional - e não à perspectiva geográfica - abrangência de um fenômeno.

Neste artigo, nos ateremos a abordagem da Escala, em sua intersecção com os componentes Espaço e Tempo na Geografia Escolar, mais especificamente, em sua abordagem para a construção de práticas pedagógicas que incorporem o conteúdo relevo (Shulman, 1986). 


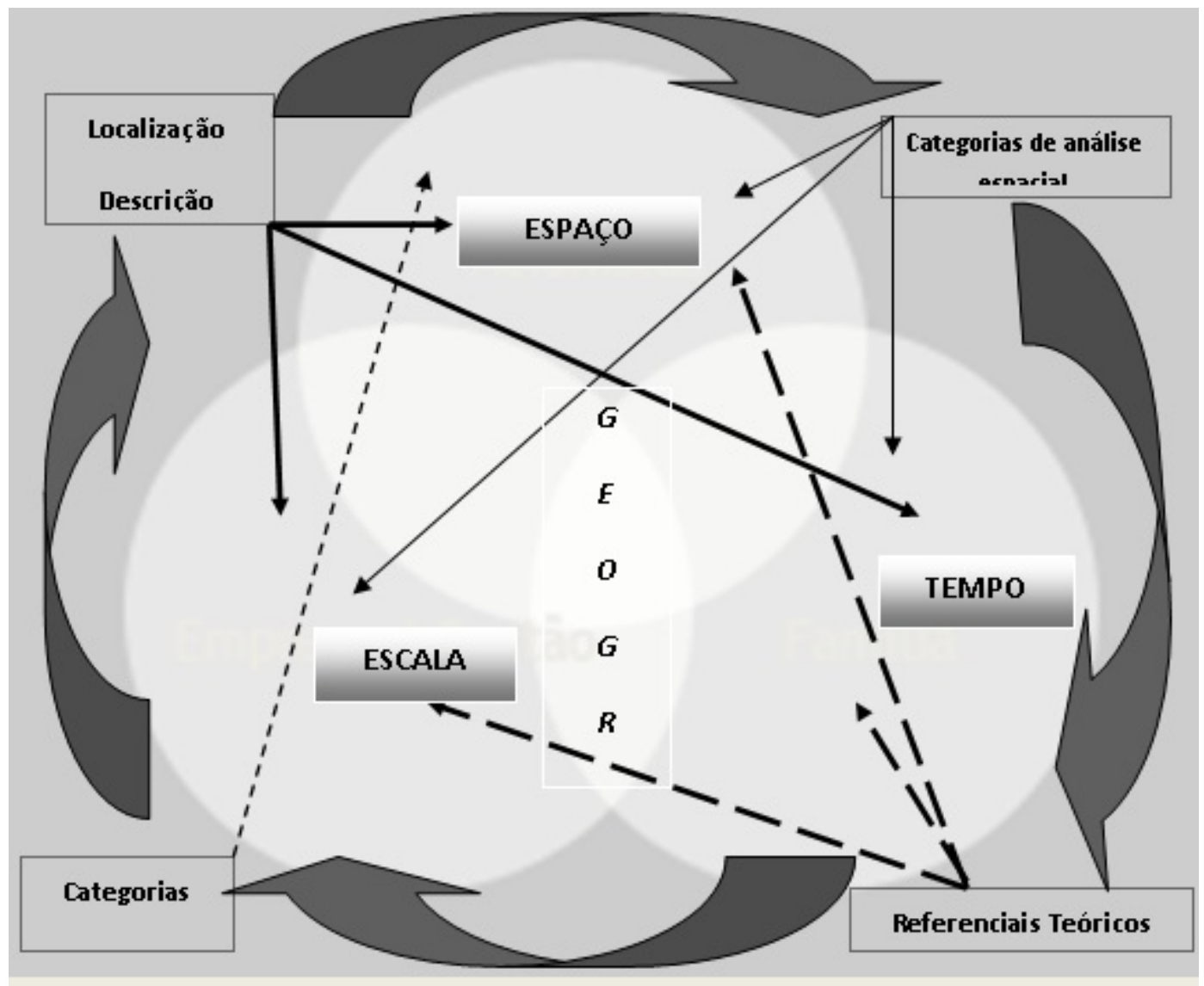

Figura 1. Constituintes da interpretação geográfica.

A escala é um referencial imprescindível à interpretação da dispersão espacial de um fenômeno. Tomada como indicador da abrangência daquilo cuja espacialização se pretende interpretar, a escala favorece a compreensão das relações de simultaneidade dos fenômenos e entre fenômenos com base na possibilidade que abre para o entendimento de possíveis paralelismos escalares: um fenômeno de mesma origem pode, ao mesmo tempo, ser local, regional, global.

Sob essa ótica, no ensino de Geografia, pode-se favorecer aos alunos a percepção de que um fenômeno de ocorrência, aparentemente local, relaciona-se com espaços outros e, em virtude desse relacionamento, sua abrangência vai além do cotidiano imediato. Local, global, regional, muitas das vezes, aparecem em interação ou em paralelo, quando se interpreta a espacialidade de um fenômeno. Nessa perspectiva, partir do local, tomá-lo como base territorial de referência (Braga, 1996) não pode ser compreendido como restringir-se ao cotidiano imediato, o que seria uma simplificação frente ao que a escala oferece à análise espacial.

Pensada para a Geografia Escolar, a escala ganha um significado sócio-cognitivo. Esse significado produz perguntas como: Qual é a finalidade do que se ensina em Geografia na educação básica? Como abordar um fenômeno frente a diferentes grupos de alunos? Tomar o local como ponto de partida é mero artifício de empiria?

O não entendimento da escala como abrangência têmporo/espacial afetará a interpretação da espacialidade de um fenômeno e, em decorrência, no caso dos geógrafos docentes, o ensino de Geografia na educação básica. Compreendida nessa perspectiva, a escala transcende a concepção de 
referencial de grandeza, muito ligado à Cartografia, e passa a ser percebida como "um jogo de relações entre fenômenos de amplitude e natureza diversas" (Castro, 1995). A depender da escala que se seleciona para análise da espacialidade de um fenômeno junto aos alunos, o professor definirá conteúdos, conceitos, procedimentos e instrumentos diferenciados. Diante disso, defende-se que a compreensão da escala como seleção, como uma opção (Callai, 2005) do docente frente a interesses sócio-cognitivos vincula-se ao entendimento do lugar da autoria do professor na elaboração do currículo a ser desenvolvido junto aos alunos.

Acredita-se que, ao se partir da escala como categoria de questionamento, associando-a com os demais constituintes da ciência geográfica pode-se suscitar reflexões metodológicas que caminhem para além "dos modos de fazer", de receituários que pouco ou nada esclarecem o sentido das opções tomadas. Utilizar o conteúdo relevo como exemplo talvez torne um pouco mais palpável aos leitores deste trabalho, os efeitos da abordagem escalar na prática pedagógica.

\section{O VIVIDO, O TRÂNSITO ESCALAR E OS CONTEÚDOS GEOGRÁFICOS}

Ao findar a leitura da obra de Gomes (1996) chegou-se a cinco conclusões relativas à ciência geográfica e que acabam por refletir sobre seu ensino na educação básica: $\mathbf{i}$ - muitos foram os que olharam para o espaço e diversas foram as "lentes" por eles utilizadas, entretanto, todos o enxergaram constituído por elementos humanos e físicos; ii - os diferentes olhares sobre o espaço tiveram sempre a preocupação quanto à localização, à descrição e à análise do que estudavam; ou seja, preocuparam-se em responder às questões, aqui entendidas, como constituintes do tripé metodológico da Geografia: Onde? Como? Por quê? iii - é possível afirmar, nos dias atuais, contando com o apoio de boa parte da comunidade geográfica que o objeto desse campo de estudos seja a dispersão do fenômeno geográfico, ou, ainda, a interpretação da espacialidade da abrangência de um fenômeno espacial; iv - ainda que possam existir, nos dias atuais, aqueles que acreditem na existência de uma metodologia única para as análises geográficas, muitos são os que apostam na diversidade para análise de diferentes fenômenos espaciais. A metodologia mais adequada para um estudo geográfico estará relacionada ao fenômeno a ser espacializado e a escala de espacialização desse fenômeno; $\mathbf{v}$ - admitir a diversidade metodológica não contradiz a afirmação de permanências nas análises geográficas, tais como as destacadas anteriormente neste texto.

Resumindo-se assim o que foi dito até agora, inicia-se a argumentação relacionando a escala selecionada para a espacialização de um fenômeno ao trabalho escolar com um dado conteúdo geográfico.

Para fins de esclarecimento, reforça-se a compreensão da espacialização como desvendamento de uma dada ordem espacial considerando-se que esta se constitui através da inteiração de diversos componentes espaciais; a ordem espacial permite a identificação da relação fenômeno/localização: quando um dado fenômeno interfere e altera um espaço e, ao mesmo tempo, quando uma dada localização interfere na atuação de um fenômeno sobre um espaço.

A escala será discutida aqui como um relevante componente para o desenvolvimento de práticas pedagógicas em Geografia na educação básica. Elegeu-se para isso uma faceta (considerada) polêmica à Geografia Escolar: o vivido como escala para o ensino dos conhecimentos geográficos. Aqui cabem algumas considerações. 
A noção de vivido carrega a ideia de visível, mas não se restringe à última perspectiva. $\mathrm{O}$ vivido pode dizer do imediato concreto, mas essa não é uma condição sine qua non. $\mathrm{O}$ vivido é uma construção social, complexa, que afirma a empiria como possibilidade para a aprendizagem, mas sem defini-la como caminho inequívoco a ser adotado. O vivido pode ser tanto ponto de partida como ponto de chegada; não é uma determinação, ainda que se defenda, que diante do inusitado para os alunos a possibilidade de ver, de sentir, de pensar sobre o que se viu, pode sem favorecer o tratamento espacial de um fenômeno.

Contudo, apesar das ressalvas anteriores, cabe questionar: É possível trabalhar a partir do vivido sem que se produza uma prática linear, progressiva, como ocorria com os círculos concêntricos? Afinal, como afirma Callai (2005): "Mundo é extremamente complexo e, em sua dinamicidade, não acolhe os sujeitos em círculos que se ampliam sucessivamente do mais próximo para o mais distante".

O vivido carrega o paradoxo da empiria e, como se afirmou, ele é, de fato, ponto de partida para abordagens outras, mas nenhum estudo geográfico pode ficar restrito a tal dimensão. Nesse momento, julga-se retomar algumas ideias piagetianas. De acordo com Piaget (1967; 1976), os sujeitos em seus processos de aprendizagem operam com duas perspectivas de abstração, a abstração empírica e a abstração reflexiva.

Com base nesse autor, afirma-se que abstrair é uma capacidade humana e todos abstraem. Entretanto, para Piaget (1976), existem dois modos de abstração correlativos entre si. O primeiro, denominado abstração empírica, refere-se à capacidade de o sujeito cognitivo refletir sobre os objetos estando em contato direto (ativo) com eles ou através de contato perceptivo (imagem, memória). $\mathrm{O}$ vivido seria assim uma escala de abordagem pautada na abstração empírica, ou seja, abstração realizada com base na experiência concreta imediata.

A abstração reflexiva opera com níveis mais complexos de raciocínio, tais como, comparação entre os diversos, associação, aplicações conceituais diante de situações distintas de aprendizagem. Mas é necessário reforçar que ambos os tipos de abstração são correlatos e não hierárquicos (Piaget, 1967).

Apoiando-se nas considerações piagetianas, afirma-se o vivido como possível início para a aprendizagem do novo e, ao mesmo tempo, como ponto de partida para as rotas que levarão a educação a situações outras, similares ou não às que se postam no vivido. Mais ainda, afirma-se que ao tomar o vivido como dimensão interpretativa da espacialidade de um dado fenômeno, a independer da idade dos sujeitos envolvidos, pode-se favorecê-los à compreensão de que aquele conteúdo nada mais é do que um dos elementos que constituem o seu real imediato, do qual se sofre ação, mas sobre o qual se pode agir.

É dessa maneira que se propõe a abordagem do conteúdo relevo na educação básica brasileira. Embora essa seja uma temática recorrente nos programas curriculares oficiais para o ensino de Geografia, e apareça no sumário da maioria dos livros didáticos dessa disciplina escolar há aproximadamente 70 anos, sua definição não é simples ou clara.

Examinando-se livros didáticos do $6^{\circ}$ ao $9^{\circ}$ ano do ensino fundamental, todos aprovados pelo Programa Nacional do Livro Didático (PNLD), encontra-se com frequência o relevo definido como 
o "resultado entre ações simultâneas entre as forças endógenas (internas) e forças exógenas" (externas). Segue-se a essa frase a explicação do que sejam forças endógenas - "(ações) provocadas pelos agentes endógenos: vulcanismos, terremotos" - e forças exógenas - "provocadas pelos agentes exógenos: água, ventos e seres vivos". Outra definição comumente encontrada nos manuais didáticos afirma que o relevo é "a camada mais superficial da Crosta da Terra, marcada por uma superfície irregular, com muitas formas e altitudes diferentes".

Afirmar tais frases como equivocadas seria um exagero, mas aceitá-las como a conceituação do que seja relevo pode ser impreciso. Entretanto, o estabelecimento de um conceito torna-se menor diante da efetiva compreensão do que seja o relevo.

A fim de definir o termo Geomorfologia, Queiroz Neto (2009) acaba por indicar que o relevo possa ser compreendido como o "conjunto de formas presentes na superfície terrestre". Segundo Guerra e Guerra (2001), tal conjunto abarca macroformas ou macrorrelevos, tais como, planaltos e depressões; mesoformas ou mesorrelevos, a exemplo das vertentes; microformas ou microrrelevos, sulcos.

Considera-se que a identificação de um conceito exato para relevo seja de importância menor para o trabalho escolar com esse conteúdo. Entretanto, trazê-la para o presente texto é relevante, pois permite evocar aspectos fundamentais para a compreensão do relevo e suas dinâmicas. Ao se aceitar como correta a proposição presente em Guerra e Guerra (2001), abre-se o caminho para o que aqui se considera ser o âmago do estudo da matéria relevo na educação básica: a discussão acerca da escala de abordagem desse fenômeno espacial, no referido nível de ensino.

Quando afirmam a existência de macrorrelevos, mesorrelevos e microrrelevos, Guerra e Guerra (2001) fazem aflorar uma discussão sensível tanto à ciência geomorfológica como ao trabalho com esse conteúdo na educação básica. Essa discussão demarca que as dimensões escalares são essenciais para se compreender o relevo na atualidade.

Confirmando a relevância do que se afirmou no último parágrafo, Suertegaray e Nunes (2001) produziram um artigo cuja uma das finalidades foi tentar responder a uma das indagações feitas atualmente no contexto desta disciplina: por que os geógrafos que trabalham com Geomorfologia basicamente não desenvolvem mais pesquisas ligadas ao estudo dos aspectos regionais, passando a valorizar as pesquisas mais pontuais e locais? (Suertegaray; Nunes, 2001, p. 17).

Esta pergunta indica que junto àqueles que se dedicam a investigar questões geomorfológicas, as quais abrangem processos de estruturação e definição de suas formas do relevo, vem havendo uma mudança na escala de abrangência, compreendida para além de uma referência de redução ou ampliação de uma área. Como afirma Kohler (2001, 21), entende-se aqui "a escala como uma técnica de abordagem de um fenômeno espaço-temporal".

A proposição da escala do vivido na análise do relevo constitui uma mudança paradigmática. Textos oficiais, tais como os PCNs (1998) e a literatura acadêmica sobre ensino de Geografia pós-década de 1990, comungam diante da necessidade de se aportar aos referenciais do vivido a fim de estabelecer o diálogo entre os educandos e aquele conhecimento que se pretende com eles trabalhar. Contudo, o exame desses documentos (Roque Ascenção, 2009) indicou que aquilo que se orienta ao professor, na maioria das vezes, não é compatível ao que se expõe como exemplo de abordagem 
pelos professores. Nesse segundo caso, as sugestões de temáticas - terremotos, vulcanismos - a serem tratadas pelos docentes estão distante das experiências imediatas da maioria dos estudantes brasileiros. Propõe-se ainda que, a partir dos temas sugeridos, os alunos venham a refletir sobre as soluções urbanas assumidas frente aos fenômenos.

Aparentemente, essa última sugestão atende aos requisitos de se construir raciocínios espaciais partindo de problemas vividos. Contudo, as vivências afetadas por terremotos e vulcanismos pouco ou nada se aproximam do cotidiano dos educandos brasileiros.

Recuperando as considerações de Guerra e Guerra (2001) referentes ao conceito de relevo, é possível afirmar que as unidades denominadas pelos autores como macrorrelevos - particularmente planaltos e depressões - tiveram sua gênese associada a processos que remontam ao Cenozoico e, em alguns casos, ao Mesozoico. Assim, a escala para a abordagem dessas (macro) formas de relevo e dos processos que as originaram e nelas ocorrem, remete a dimensões, espaciais e temporais que não são apreendidas através da observação, através do visível.

Neste trabalho, defende-se que o ensino de relevo, sobretudo, no segundo segmento do ensino fundamental (quando se inicia um trabalho conceitual mais profundo) deva se apoiar no vivido e no visível. Infere-se que tal escala beneficie aos alunos a elaboração de hipóteses para os processos que dão origem ao modelado. Por certo, muitas serão as hipóteses visto que a aula é uma ação coletiva. Algumas dessas hipóteses poderão estar aportadas em interpretações do senso comum. Nesse momento, ganha protagonismo a figura docente, a qual caberá fazer interagir, instigando novas hipóteses e respostas, contribuindo para o desenvolvimento de respostas lógicas que, efetivamente, expliquem os problemas encontrados no vivido.

De acordo com Kohler (2001, p. 22), "a dimensão do evento [geomorfológico] aumenta com o tempo, e o tempo necessário para o seu desenvolvimento também cresce". Compreende-se, a partir de Kohler (2001), que para a identificação de uma forma de relevo e a compreensão dos processos que lhe deram origem toma-se tempo e espaço diretamente proporcionais, ou seja, tempos longos, grandes dimensões espaciais; tempos curtos, pequenas dimensões espaciais.

Sob essa lógica entende-se que o estudo das macroformas exige um longo deslocamento temporal para a compreensão de seus processos constituintes, presente no vivido, mas invisível aos alunos. Ao mesmo tempo, dizem respeito a formas de relevo não prontamente visíveis por meio da paisagem, categoria geográfica que em muito contribui para a escala do vivido.

Sugere-se, assim, que na educação básica o trabalho com o relevo e suas dinâmicas contemplem as mesoformas, tais como as vertentes. Essa forma favorece, por exemplo, a identificação de processos denudacionais e deposicionais, que se repetem nas macroformas, podendo assim beneficiar o trabalho paralelo com diferentes abrangências escalares. As vertentes registram, na dimensão do vivido e do visível, a suscetibilidade humana diante das condições naturais. Se for fato que o homem transforma e atua sobre os componentes naturais do espaço, não se pode negar que, ainda hoje, ele está condicionado ao funcionamento da natureza. Um exemplo do que se disse está na ocupação das vertentes, áreas de risco, que há todo momento deixam à mostra as fragilidades de alguns planejamentos urbanos.

Casseti (2008) sugere a vertente como a forma de relevo através da qual se estudarão determinados processos e adverte que considerar essa escala espacial não significa restringir as análises ao 
tempo atual ou das formas visíveis. O autor enfatiza a relevância dessa escala justamente por permitir, também, a abordagem do tempo histórico-humano, no qual ocorrem as apropriações espaciais e o qual permite visualizar os efeitos mais imediatos dessas apropriações. Sob esse aspecto, o estudo de tal conteúdo pode ganhar significado social efetivo e, talvez, favorecer a compreensão e ampliação dos conhecimentos geográficos como "lentes" que possibilitam a leitura do real.

A vertente seria assim a forma que atenderia a uma escala do vivido. Outras formas poderão cumprir esse papel, a depender da área onde o estudo for realizado. O mais importante é que a tomar essa forma visível como base territorial de referência seja possível permitir aos educandos a construção de hipóteses acerca dos processos de estruturação do modelado. Tais hipóteses coletivizadas e mediadas pelos conhecimentos docentes podem contribuir para o entendimento do relevo como uma construção cotidiana, passível da ação humana e, nem sempre, ligados aos grandes eventos tectônicos. A questão central não é ter o vivido como princípio, mas, sim, garantir que a partir daí os sujeitos possam interagir com vivências de outros, com base no movimento de identificação de semelhanças e diferenças, por exemplo. $\mathrm{O}$ vivido, nessa perspectiva, seria uma base a partir da qual se produziriam questionamentos ligados ao imediato concreto ou não.

A vertente, ou outra forma do vivido, referem-se à escala social (Callai, 2005); escala do tempo histórico, do tempo do olhar humano e da observação empírica. Essa escala (do vivido) facilita que o professor demonstre aos seus alunos a interação permanente entre componentes físicos e humanos, e, consequentemente, permita-os acessar como tais interações constituem as espacialidades nas quais eles se inserem.

Ao se considerar o vivido como ponto de partida para a abordagem do relevo e suas dinâmicas, realiza-se um deslocamento quanto à escala espaço-temporal, passando-se assim a considerar tempos curtos e pequenos espaços como recorte para os estudos. Tal deslocamento escalar reverbera no deslocamento da ênfase dos estudos. Os trabalhos estarão menos dedicados à compreensão da origem de uma forma de relevo invisível no vivido, voltando-se para a compreensão dos processos que ocorrem em formas visíveis do relevo (Casseti, 2008). A ênfase de tais estudos não será mais na morfogênese, mas, sim, na morfodinâmica.

Segundo Casseti (2008, s/p), a "morfodinâmica" reporta às relações processuais numa perspectiva histórica em que o homem se constitui no principal agente das alterações. Estudos considerando a morfodinâmica favorecem a compreensão sistêmica do espaço, ou seja, a ênfase na morfodinâmica pode favorecer a compreensão da espacialização do relevo. Esse componente espacial pode assim ser entendido na interface com outros componentes, tais como, a vegetação, a hidrografia e, em particular, o homem.

Considera-se, assim, que tomar o vivido e os processos morfodinâmicos como ponto de partida para a espacialização do relevo pode favorecer aos educandos a compreensão da articulação entre a frequência e a intensidade das chuvas, as condições de preservação da cobertura vegetal e o tipo de ocupação realizada numa vertente.

Os processos morfodinâmicos dizem respeito à dinâmica do relevo, entretanto, essa origem reporta-se a tempos curtos, valorizando-se "a análise dos processos no tempo que faz (curtos), muito mais do que no tempo que escoa (longo)" (Suertegaray, 2002, p. 4). 
Infere-se que o deslocamento escalar espaço-temporal, que toma, por exemplo, a vertente como recorte espacial para análise do relevo, pode permitir que educandos venham a compreender o valor social desses conhecimentos, bem como a inserção do homem como agente construtor do espaço geográfico.

Em decorrência, os educandos poderão entender sua implicação e dos demais sujeitos sociais em eventos, cuja compreensão, por vezes, fica restrita à ação dos componentes físicos do espaço, tais como o desmoronamento de encostas. Como Casseti (2008), considera-se esse evento como consequência dos "efeitos pluvioerosivos nas regiões intertropicais", cuja principal característica é "a ação das duas estações (seca e chuvosa)" (Casseti, 2008, s/p.), que associados às ações de desmatamento pelo homem com fim de ocupação para moradia, construção de estradas, ocupação agrícola, acabam por provocar erosões ou a aceleração de processos erosivos.

O que se propõe aqui não é o abandono das macroformas nas aulas de Geografia da educação básica, mas, sim, uma perspectiva metodológica que reconheça no vivido oportunidades para o entendimento do não vivido. A ideia é trazer o não vivido ao vivido. Continuamente. Sempre que a temática a ser espacializada carregar um forte ineditismo, sempre que os sujeitos sociais, ou seja, os educandos demandarem essa dimensão escalar em sua aprendizagem.

\section{CONSIDERAÇÕES FINAIS}

Muito há que se aprofundar nos debates metodológicos acerca da Geografia Escolar. O que se pretendeu neste trabalho foi lançar uma pequena fagulha, tomando a escala geográfica como foco para a análise.

Reconhece-se a incompletude das ideias aqui contidas e pretende-se investir em seu aprofundamento.

Entretanto, não se finalizará este artigo realizando uma síntese do que se apresentou ao longo do texto. Ao contrário, optou-se por, neste momento, trazer à tona questionamentos suscitados pela pesquisa e, compreende-se, fundamentais para o aprofundamento dos debates referentes ao ensino de Geografia e, mais detidamente, sobre a formação docente geógrafo:

- Por que a escala do vivido, ainda hoje, indiferente ao que orientam documentos oficiais e estudos acerca da Geografia Escolar, raramente aparece nas práticas pedagógicas dessa disciplina? Sobretudo quando se pensa no segundo segmento do ensino fundamental e no ensino médio?

- Em situação inversa à anterior, por que a referida escala, ao ser selecionada como opção de interpretação espacial de um fenômeno, na maioria absoluta das vezes, fica restrita ao imediato concreto, não favorecendo ao educando o olhar sobre o fenômeno através do trânsito escalar?

- Estariam os cursos formadores dos geógrafos docentes e, inerentemente, os formadores que neles atuam, trabalhando de modo a contribuir para que os futuros professores venham a operar na perspectiva metodológica sugerida neste artigo? 
Deixa-se assim registrados os incômodos constantes de uma formadora, na expectativa de encontrar pares e assim alargar o que se começou aqui a debater.

\section{BIBLIOGRAFIA}

Almeida, R. D. (1994). Uma proposta metodológica para a compreensão de mapas geográficos. $367 \mathrm{p}$. Tese (Doutorado em Educação) - Faculdade de Filosofia e Letras da Universidade Ciências Humanas, Universidade de São Paulo, São Paulo.

. (1996) A estruturação do discurso pedagógico: classe, códigos e controle. Petrópolis: Vozes.

Braga, R. B. (1996). Construindo o amanhã: caminhos e descaminhos dos conteúdos geográficos na escola elementar. 257 p. Tese (Doutorado em Geografia Humana) - Faculdade de Filosofia, Letras e Ciências Humanas, Universidade de São Paulo, São Paulo.

Casseti, V. Geomorfologia. Disponível em < http://www.funape.org.br/geomorfologia/index. php> . Acesso em: 11 nov. 2008.

Castellar, S. M. V. A psicologia genética e a aprendizagem no ensino de Geografia. In: Castellar, S. M. V. (Org.) (2006). Educação Geográfica: teorias e práticas docentes. São Paulo: São Paulo, 38-50.

. (2005). Educação Geográfica: a psicogenética e o conhecimento escolar. Caderno Cedes, Campinas, 25 (66) 209-225. Disponível em: <http://www.cedes.unicamp.br>. Acesso em: fev./mar. 2009.

Corrêa, R. L. Espaço: um conceito-chave da Geografia. In: Castro, I. E. et al. (1995). Geografia: conceitos e temas. 5. ed. Rio de Janeiro: Bertrand Brasil.

Cavalcanti, L. S. (1996). A construção de conceitos geográficos no ensino. Uma análise de conhecimentos geográficos de alunos de $5^{\mathrm{a}}$ e $6^{\mathrm{a}}$ séries do ensino fundamental. 295p. Tese (Doutorado em Geografia Humana) - Faculdade de Filosofia, Letras e Ciências Humanas, Universidade de São Paulo, São Paulo.

. (2002). Geografia e práticas de ensino. Goiânia: Alternativa, 2002.

Chevallard, Y. (1991). La Transposition Didactique: Du Savoir Savant au SavoirEnsigné. Grenoble, La penséeSauvage.

Gomes, P. C. C. (1996). Geografia e Modernidade. Rio de Janeiro: Bertrand Brasil.

Gomes, P. C. C. Um lugar para a Geografia: contra o simples, o banal e o doutrinário. In: Mendonça, F. et al. (Org.) (2009). Espaço e Tempo: complexidade e desafios do fazer geográfico. Curitiba: ADEMAN, 13-30.

Kohler, H. C. (2001). A escala na análise geomorfológica. Revista Brasileira de Geomorfologia, Uberlândia, 2, 21-33. 
Marques, J. S. Ciência Geomorfológica. In: Guerra, A.; Cunha, S. Geomorfologia - uma atualização de bases e conceitos. (2003). Rio de Janeiro: Bertrand Brasil, 23-50.

Peloggia, A.U.G. (2005). A cidade, as vertentes e as várzeas: a transformação do relevo pela ação do homem no município de São Paulo. Revista do Departamento de Geografia, 16, 24-31.

Piaget, J.; Inhelder, B. (1993). A representação do espaço na criança. Trad. Bernadina Machado de Albuquerque. Porto Alegre: Artes Médicas, 1993.

Piaget, J. (1976). A equilibração das estruturas cognitivas - problema central do desenvolvimento. Rio de Janeiro: Zahar Editores, 1976.

Queiroz Neto, J. P. Geomorfologia e Pedologia. Disponível em: <http://www.geografia.fflch.usp. br/publicacoes/Geousp/Geousp13/Geousp13_Queiroz.htm>. Acesso em: jun. 2009.

Roque Ascenção, Valéria de O. (2009). Os conhecimentos docentes e a abordagem do relevo e suas dinâmicas nos anos finais do ensino fundamental. 2009. Tese de Doutorado (Instituto de Geociências), Universidade Federal de Minas Gerais. Disponível em: <http://www.bibliotecadigital.ufmg. $\mathrm{br} /$ dspace/bitstream/1843/MPBB-7Y5MBJ/1/valeria_tesefinal_completa.pdf> Acesso: maio 2010.

Santos, M. Espaço \& Método. (1997). 4. ed. São Paulo: Nobel, 1997.

Shulman, L. S. (1986). Thosewhounderstand: knowledgegrowth in teaching. EducationalResearcher, Washington, 1986, 15(2) 4-14.

Silva, C. R. B. S. Desenvolvimento profissional de professores de Geografia: contribuições de um grupo de estudos sobre o ensino da localidade. Disponível em: < http://servicos.capes.gov.br/capesdw/>. Acesso em: 20 ago. 2008.

Straforini, R. (2002). Ensinar Geografia nas séries iniciais: o desafio da totalidade mundo. (Dissertação de Mestrado). Universidade Estadual de Campinas, Instituto de Geociências: Campinas, 2002.

Suertegaray, D. M. A. (2008). Geografia Física e Geomorfologia: temas para debate. In: VII Simpósio Nacional de Geomorfologia e II Encontro Latino-Americano de Geomorfologia. Belo Horizonte: VII Simpósio Nacional de Geomorfologia e II Encontro Latino-Americano de Geomorfologia. UFMG1, 1-14.

. (2001). Espaço Geográfico Uno e Múltiplo. Scripta Nova, Barcelona, 93.

. (2005). O atual e as tendências do ensino e da pesquisa em Geografia no Brasil. Revista do Departamento de Geografia (USP), São Paulo, 16, 38-45.

. (2002). Tempos longos... Tempos curtos... Na análise da natureza. Geografares, Vitória (3), 159-163.

. (2002). Geografia Física e Geomorfologia. Uma (Re) leitura. Ijuí: Ed. Unijuí. 
Veloso, A. J. G. (2002). A importância do estudo das vertentes. In: Revista Geographia. Publicação da Universidade Federal Fluminense. Ano IV (8). Disponível em: <http://www.uff.br/geographia/rev_08/antonio8.pdf>. Acesso em: 15 mar. 2009.

Artículo recibido 20 - 09 - 11. Aprobado 25 - $11-11$. 